Sharif University of Technology
Scientia Iranica
SCIENTIA
I RAN I CA

\title{
Improving Critical Path Method (CPM) by applying safety factor to manage delays
}

\author{
A. Moghayedi* \\ BSCE, MSCM, MSCE, College of Engineering, University of the Philippines, Philippines.
}

Received 17 September 2014; received in revised form 15 June 2015; accepted 26 September 2015

\author{
KEYWORDS \\ Critical path method; \\ Color coding; \\ Delay; \\ Injuries and illnesses; \\ Safety Factor; \\ Risk.
}

\begin{abstract}
Compared to other industrial endeavors, the construction industry has the highest percentage rate of injuries and illnesses severely causing construction delays. The Critical Path Method (CPM) scheduling technique was considered to control and monitor construction activities to meet the project deadlines, effectively, but not to control and monitor the project in terms of forecasted injuries and illnesses. The researcher proposed to develop a solution by deriving the Safety Factor to manage delays. The Safety Factor originated from the statistics of injuries and illnesses through classification of the annual percentage rate of the construction activities. Five color coding categories were formulated, guiding the users towards early detection of risks level in the CPM diagram, enabling immediate action, and lessening the adverse impact on the entire construction process. The research focused on getting back to the normal time schedule as-planned when disruptive injuries and illnesses occurred by using a Safety Factor, in which more dynamic CPM techniques were included in the formulation of the Safety Factor, therefore, increasing construction safety and decreasing construction risks.
\end{abstract}

(C) 2016 Sharif University of Technology. All rights reserved.

\section{Introduction}

Although construction industry continuously disseminates safety awareness drive, such as issuing safety programs and manuals, using new safety tools, conducting and/or attending construction safety seminars, and trainings to avoid injuries and illnesses, the rate of injuries and illnesses in the construction industry is still escalating significantly leading to increased project duration and cost. Not to mention, the required implementation and practice of the CPM scheduling technique to maximize profit, to finish the project earlier or on time with the prescribed quality, and particularly to avoid delay are proven as an effective tool in planning, controlling, and scheduling the span of construction activities [1]. But, it still does not

*. Tel.: +9851 37642257; Fax: +98-51-38418700

E-mail address: akm.moghayedi@gmail.com forecast any delay due to accident, particularly injuries and illnesses.

Typically, delays are managed simply in the construction industry by recording the delay(s), calculating the number of days for each delay and adding it up into the total number of delayed days, requesting for a time extension equivalent to the total number of delayed days, and paying the penalty per day. Not managing the delay and waiting until chaos/disputes occur results in arbitration or any other legal approach, and loss of money and time by all parties [2].

The researcher strongly disagrees on these kinds of approaches for managing delays; however, after 3 consecutive years of intensive research and presentation to develop a new technique using the Critical Path Method (CPM), scheduling technique, as a major tool to manage construction delays, has revealed so many advantages and great potential for another scheduling technique(s) in future studies as well.

According to Bubshait [3], delay measurement 
process indicates that the outcomes of delay analyses are not predictable, nor can one method be used universally. These procedures were employed to measure delay impact, utilizing computerized Critical Path Method (CPM) analyses performed on genuine construction schedules.

These procedures are evidently essential in analyzing and deriving CPM technique in the construction project(s) to manage the delays, as Bubshait [2] stated that: Network-based scheduling is an excellent vehicle for negotiating settlement of changes, disputes, and particularly delays throughout the project. With this, the researcher used these ideas to develop a new approach of managing delays, caused by the accident, by incorporating the factors of safety derived from the degree of injuries and illnesses of the construction activities to have a genuine construction schedule as Bubshait [2] mentioned.

$\mathrm{Yi}$ and Langford [4] presented the concept of combined effect of different risk factors on the accident. For proper safety planning, safety managers need to be well aware of the direct causes of the accident as well as indirect factors that adversely affect site safety. If it is observed that a hazardous environment exists in the site, then either that hazardous environment must be eliminated or occupations and processes related to that hazard must be properly protected. One of the measures for evading such hazardous situations is to predict such situations and reschedule the start time of high-risk situation so that risks are not concentrated during certain periods and at certain locations. In order to predict when and where the risk reaches its highest level, analysis should be performed based upon various information, including statistical sources such as accident histories, and this should be done in coordination with activity scheduling.

Normally, it is known that the best safety performances are found in construction projects that use sophisticated scheduling data, frequently update project schedule, are wholly coordinated meeting, and maintain the project schedule. That concept made the researcher focus on the construction process with regard to safety in evaluating the most recorded injuries and illnesses to formulate Safety Factor to manage the delays in a unit, which is advantageous to the beneficiaries as construction professionals.

To implement ideas of Yi and Langford [4], the researcher categorized the injuries and illnesses in accordance with their effect in Color Coding Categories to determine the precautionary measures that need to be implemented and, most of all, to determine their respective factor of safety that were to be reflected in the CPM diagram to recover the delays lost by the injuries and illnesses.

Also, the planning method of Winch and North [5] is very relevant to this study, mainly because of its unique analysis and planning the sequence of tasks and how to manage the construction space scheduling problem on site, which the researcher used in the unique ideas on improving the Critical Path Method. Sophisticated methods of planning and analyzing the sequence of tasks within the work break the structure down through time, but the problem of planning where the tasks are to be executed onsite is not wellsupported, especially because the spaces are dynamic as the project progresses. We know that congestion on site reduces output and generates hazards, yet construction planners presently have to rely upon experience and intuition.

Using the concept of Winch and North [5], the researcher will maximize the construction activities in the dynamic approach through calculation of safety duration, particularly in critical activities, and notice the space difference from the normal duration to the safety duration.

Saurin et al. [6] are eager to improve the safety awareness in the construction industry through integrating safety into the production planning and control process, which they call Safety Planning and Control (SPC) model; they state that: The main features of a Safety Planning and Control (SPC) model were proposed. Among the safety management improvements introduced by the model, one of the most important ones is the simplification of the safety planning procedures. The aim is that safety planning and control do not make normal planning meetings very timeconsuming. The integration should not be dependent on the use of any specific production planning model. It should only require a formal planning system which is characterized by planning hierarchy, continuity, and participation.

In light of the above, the researcher is enthusiastic to develop its own technique of improving and developing the construction safety through the use of Critical Path Method (CPM) Scheduling Technique. The technique is particularly useful and it will provide a model of the project or a master plan. It illustrates how a project is originally planned and how it changes as the project progresses.

\section{Research method and framework}

As the framework of the study, the researcher anchored the unique ideas of managing construction delays caused by the injuries and illnesses that occur on the construction site as follows:

1. Non-fatal injuries and illnesses recorded in the Bureau of Labor Statistics (2001-2013) in accordance with the accident rate in the Construction Industry of the United States of America is the primary source of classifying and categorizing the different 
injuries and illnesses that occur in construction sites; the statistic factor and probability of the construction activities will be analyzed with high and low accident rates. Each accidents rate will be studied and the root of accident in a particular construction activity will be highlighted;

2. Incorporating construction safety into the CPM Scheduling Technique using the Color Coding Categories and the Safety Factor (SF) was done by deriving the statistics of injuries and illnesses from the primary source. It is essential to consider the rate of accident in planning and scheduling the construction activities to forecast their pessimistic scenarios in order to manage the construction delays using dynamic approach.

The study was conducted with the use of registered method of research. Considering the objective of the study, the registered method of research is the most appropriate to use: "Registration is a process of listing down items of the same kind in some systematic manner for record purposes". [7]

To analyze and derive the ideal factor of safety, the researcher used the optimistic rate and the pessimistic rate of non-fatal injuries and illnesses statistics of BLS (2001-2013). He also considered the critical path and the non-critical path in the CPM diagram in order to determine the ideal factor of safety in a particular line or activity.

Documentary analysis is very vital in this study to determine the needs of construction industry; also, it is necessary for the person involved in planning and scheduling of the construction activities to avoid delays caused by injuries and illnesses that occur in construction site.

In general, the registered method, interview, observations, and documentary analysis have helped the researcher gather objective information on developing a new unique technique in managing the delays caused by the injuries and illnesses that occur in construction projects through the use of master plan, commonly known as CPM.

\section{Derivation of Safety Factor (SF)}

Surveys and interviews were provided with different construction managers and technical experts involved in the construction industry to verify the elements that were necessary in calculating the probable delay of each construction activity due to injuries and illnesses, namely Number of Manpower, Duration of Activity, and the Potential Hazards of Activities Depending on the Project Size.

As a result, Safety Factor (SF) is the product of the number of manpower $(\mathrm{Nm})$, project duration $(T)$, factored size of manpower (Fsm), and the average rate of injuries and illnesses (Rave) of the stated activity in the CPM diagram. Safety Factor is the multiplier to the original activity duration to forecast the accident delay in any of the construction activities through equal distribution of the delays in all critical activities.

The Safety Factor focuses on the critical activity because there is no allowance or extra time in these activities unless the project incorporates dummy activities to cover the probable injuries and illnesses.

The determination and derivation of construction Safety Factors is an advanced and dynamic approach for effective management of the construction safety, particularly the construction delays, with the aid of construction categories which should be used in each phase of the construction project (pre-construction, during construction, and post-construction) from the start to the end. This enables forecasting the injuries and illnesses to avoid the uncontrollable effect of delays from one construction activity to the succeeding activities.

The Safety Factor critical (SFc) is the computed probable delay of critical activities along the critical path without float, or zero float, with the working equation shown below:

$$
S F c=N m c \times F s m \times T \times R c . a v e,
$$

where:

$\begin{array}{ll}S F c & \text { Safety Factor of critical path } \\ N m c & \begin{array}{l}\text { Number of manpower in critical } \\ \text { activities. }\end{array} \\ T & \begin{array}{l}\text { Project duration } \\ F s m\end{array} \\ \text { Factored size of manpower } \\ \text { Rc.ave. } & \begin{array}{l}\text { Average rate of injuries and illnesses of } \\ \text { critical activities }\end{array}\end{array}$

Number of the manpower ( $\mathbf{N m})$. The number of manpower to complete the activity on schedule. One unit of manpower is equivalent to 8 man-hours.

Factored size of manpower (Fsm). The number of manpower working daily in the project. This factor comes from the incident rate of injuries and illnesses based on the size of the project. Fsm is necessary in determining the real number of the manpower.

The researcher classified the entire construction project into 5 manpower size classes, same as what has been used in United States Department of Labor, as shown below in Table 1 .

With this, the factored size of manpower in the construction industry (Fsm) was computed using the equation below:

$$
F s m=I c \times I m,
$$

where Fsm is factored size of manpower; Ic is average 
Table 1. Number of manpower per project size.

\begin{tabular}{cc}
\hline $\begin{array}{c}\text { Project size, } \\
\boldsymbol{P S}\end{array}$ & $\begin{array}{c}\text { Number of manpower } \\
\text { per day, } \boldsymbol{N m}\end{array}$ \\
\hline Size 1 & $1-10$ manpower \\
Size 2 & $11-49$ manpower \\
Size 3 & $50-249$ manpower \\
Size 4 & $250-999$ manpower \\
Size 5 & $1000+$ manpower \\
\hline
\end{tabular}

incident rate of injuries and illnesses in construction industry; and $I m$ is incident rate of injuries and illnesses of each project size.

The factored size of manpower (Fsm) in construction industry for each Project Size (PS) was based on the statistics of injuries and illnesses recorded by BLS from year 2001 to year 2013; these statistics are computed and summarized in Table 2 [8].

Project duration $(\boldsymbol{T})$ is the elapsed time from the project start date to project end date, which is also reflected in the CPM diagram.

Average rate of injuries and illnesses of each activity (Rave) is the actual average percentage rate of injuries and illnesses of each of the 25 construction activities that have been derived from the recorded number of injuries and illnesses occurred in the specific construction activities and total number of injuries and illnesses in construction industry as categorized from year 2001 to year 2013 by the Bureau of Labor of Statistics (BLS 2001-2013), as illustrated in Table 3 [8].

$$
\text { Annual percentage }=\frac{\text { Number of injuries }}{\text { Total injuries }} \times 100 \% \text {, }
$$

where number of injuries is number of injuring activities in year, and total injuries is total injuries in year.

Based on the average rate of 25 construction activities (BLS 2001-2013), the most risky activity is the plumbing contractors, $14.27 \%$, and the least risky activity is the siding contractors, $0.42 \%$. The higher the average rate of injuries and illnesses, the more risky the activities are.

Table 2. Factored size of manpower in construction industry.

\begin{tabular}{cc}
\hline Project size, $\boldsymbol{P S}$ & $\begin{array}{c}\text { Factored size } \\
\text { of manpower, } \boldsymbol{F ~ s m}\end{array}$ \\
\hline Size 1 & 1.860 \\
Size 2 & 3.900 \\
Size 3 & 5.516 \\
Size 4 & 5.018 \\
Size 5 & 4.942 \\
\hline
\end{tabular}

Therefore, the Safety Factor for critical path of the project is determined after all the incorporated elements are derived and defined. Thereafter, the delay for each critical activity is calculated as actual duration and delay. Finally, the new project duration is determined. The improved CPM should reflect the color coding of safety for each activity, which will be discussed in the next section, incorporated by appropriate safety process and risk process. Once the Safety Factor is used in the CPM, it will automatically integrate the new technique of construction safety management, as illustrated in the next section.

\section{Five color coding categories}

To easily identify the risk level of activities, the researcher assigned color codes of Risk Matrix on PMBOK Guide [9] to five categories represented in Table 4 as C1, C2, C3, C4, and C5 depending on the percentage rates or degrees of injuries and illnesses of each construction activity that were computed in the previous section. For instance, $\mathrm{C} 1$, represented by green color, has the least percentage rate of injuries and illnesses, $0.01 \%$ to $3.00 \%$, that means activities like land subdivision (0.57\%); structural steel and precast concrete contractors $(1.91 \%)$, etc. have very low probabilities of injuries and illnesses which may occur during the construction. On the other hand, C5, represented by red color, has the highest percentage rate of injuries and illnesses, $12.01 \%$ and above, that means activities like plumbing, heating, and airconditioning contractors $(14.27 \%)$ have the highest probability of injuries and illnesses which may occur during construction.

As shown in Figure 1, the corresponding Risk Matrix on PMBOK Guide [9] color codes is based on five color coding categories in the construction industry, which easily distinguishes the critical activities and incorporates the necessary precautionary measures or actions in the planning stage of construction.

In relation to the categories of rate of injuries and illnesses, as discussed earlier, the researcher created the safety management process and risk management process based on risk process classification of Risk Impact Matrix on PMBOK Guide [9], which is shown in Table 5, to continuously improve and develop the awareness in the construction industry, particularly on the nonfatal injuries and illnesses that may occur in site.

The Five Steps of Safety Process [10] and Risk Process [11] are vital to assess the construction activities as well as the whole construction project, especially before the construction starts, in order to anticipate the impact on project duration and project cost caused by the precautionary measures or actions needed to avoid, if not to eliminate, the injuries and illnesses. 
Table 3. 25 activities in the construction industry and average rate of injuries and illnesses of each activity.

\begin{tabular}{|c|c|c|}
\hline No. & Activities & Average \\
\hline $\mathbf{A}$ & Construction of buildings & \\
\hline 1 & Residential building construction & $7.54 \%$ \\
\hline 2 & Nonresidential building construction & $10.73 \%$ \\
\hline $\mathbf{B}$ & Heavy and civil engineering constructions & \\
\hline 3 & Utility system construction & $6.13 \%$ \\
\hline 4 & Land subdivision & $0.57 \%$ \\
\hline 5 & Highway, street, and bridge construction & $6.99 \%$ \\
\hline 6 & Other heavy and civil engineering constructions $1.38 \%$ & \\
\hline $\mathrm{C}$ & Specialty trade contractors & \\
\hline C. & Foundation, structure, and building exterior contractors & \\
\hline 7 & Poured concrete foundation and structure contracts & $5.02 \%$ \\
\hline 8 & Structural steel and precast concrete contractors & $1.91 \%$ \\
\hline 9 & Framing contractors & $4.06 \%$ \\
\hline 10 & Masonry contractors & $3.01 \%$ \\
\hline 11 & Glass and glazing contractors & $1.40 \%$ \\
\hline 12 & Roofing contractors & $3.62 \%$ \\
\hline 13 & Siding contractors & $0.42 \%$ \\
\hline 14 & Other foundation, structure, and building exterior contractors & $0.76 \%$ \\
\hline C. & Building equipment contractors & \\
\hline 15 & Electrical contractors & $9.22 \%$ \\
\hline 16 & Plumbing contractors & $14.27 \%$ \\
\hline 17 & Other building equipment contracts & $1.43 \%$ \\
\hline C. & Building finishing contractors & \\
\hline 18 & Drywall and insulation contractors & $6.87 \%$ \\
\hline 19 & Painting and wall covering contractors & $1.60 \%$ \\
\hline 20 & Flooring contractors & $0.72 \%$ \\
\hline 21 & Tile and terrazzo contractors & $1.19 \%$ \\
\hline 22 & Finishing carpentry contractors & $2.19 \%$ \\
\hline 23 & Other building finishing contractors & $1.11 \%$ \\
\hline C. & Other specialty contractors & \\
\hline 24 & Site preparation contractors & $3.60 \%$ \\
\hline 25 & All other special contractors & $4.28 \%$ \\
\hline Total & & $100.00 \%$ \\
\hline
\end{tabular}

Table 4. Five color coding categories in construction industry.

\begin{tabular}{cccc}
\hline Category (C) & $\begin{array}{c}\text { Rate of injuries } \\
\text { and illnesses (\%) }\end{array}$ & Color codes & Remarks \\
\hline C1 & $0.01 \%-3.00 \%$ & Green & Least \\
C2 & $3.01 \%-6.00 \%$ & Blue & Less than minimal \\
C3 & $6.01 \%-9.00 \%$ & Yellow & Minimal \\
C4 & $9.01 \%-12.00 \%$ & Orange & Less than maximum \\
C5 & $12.01 \%$ above & Red & Maximum \\
\hline
\end{tabular}




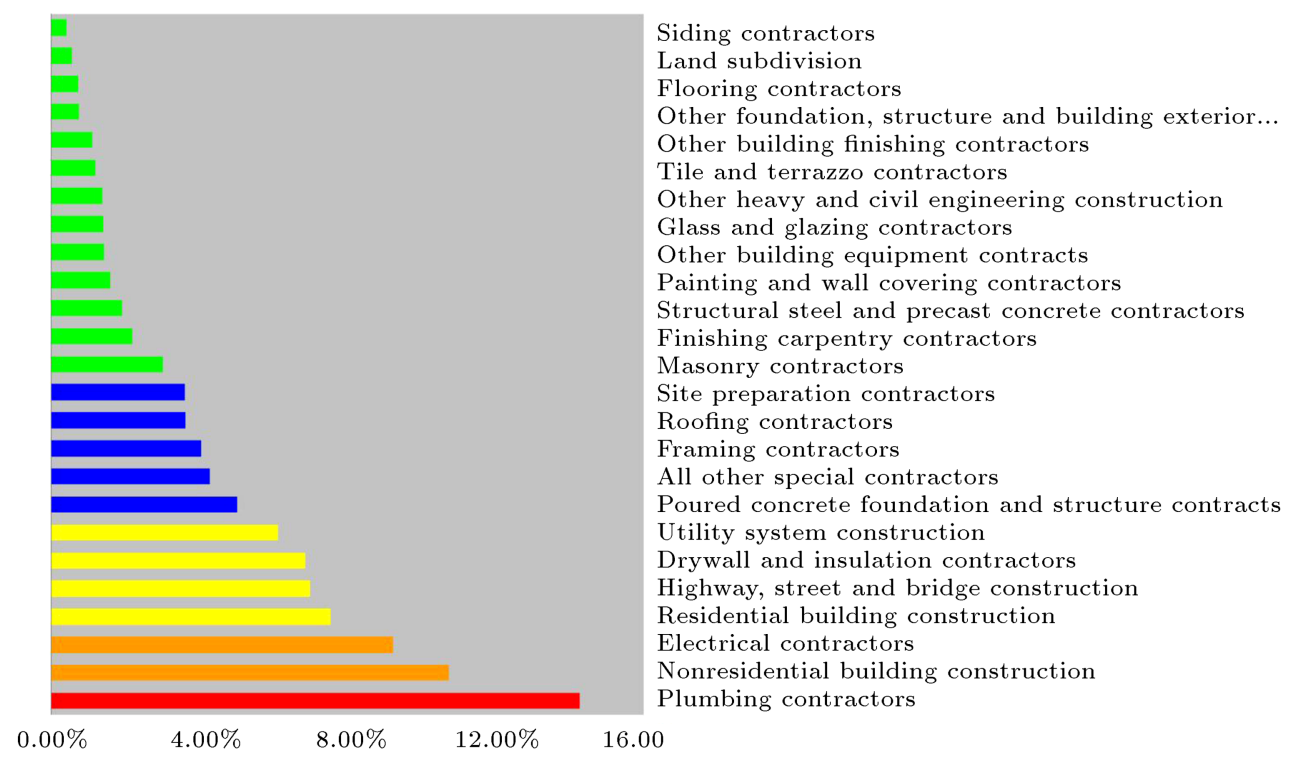

Figure 1. The color coding of 25 activities in the construction industry based on average rate of injuries and illnesses (2001-2013).

Table 5. Five steps of safety process and risk process.

\begin{tabular}{|c|c|c|}
\hline Accident category & Safety process & Risk process \\
\hline $\mathrm{C} 1$ & Follow the safety program & $\begin{array}{c}\text { Accepted (risk level of } \\
\text { these activities } \\
\text { are acceptable) }\end{array}$ \\
\hline $\mathrm{C} 2$ & $\begin{array}{l}\text { Monitor closely these activities } \\
\text { with the safety manager }\end{array}$ & $\begin{array}{l}\text { Retention (risk level } \\
\text { is still acceptable for these } \\
\text { activities, but needs allocation } \\
\text { from contingency budget) }\end{array}$ \\
\hline C3 & $\begin{array}{l}\text { Use trained workers } \\
\text { in these activities }\end{array}$ & $\begin{array}{l}\text { Reduction (risk level } \\
\text { reduced by using trained workers) }\end{array}$ \\
\hline $\mathrm{C} 4$ & $\begin{array}{c}\text { Innovate an adequate technology for } \\
\text { these activities }\end{array}$ & $\begin{array}{c}\text { Avoidance (risk avoided by innovating } \\
\text { new technology) }\end{array}$ \\
\hline C 5 & $\begin{array}{l}\text { Transfer the activities to } \\
\text { an expert contractor }\end{array}$ & $\begin{array}{c}\text { Sharing (risk transferred } \\
\text { or shared with others) }\end{array}$ \\
\hline
\end{tabular}

\section{Case study}

To illustrate the application of the Safety Factor in the Critical Path Method (CPM) and highlight the difference in terms of time, cost, the functions regarding management, and the overall benefits of applying Safety Factor in construction project, this research employed the Safety Factor CPM in an actual project in the U.S. that experienced 2 incidents of injuries and illnesses with the following project specifications:

- Project contract cost: USD 150,000.00;
- Project duration $(T)$ : 30 weeks;

- Average daily cost: USD 833.33;

- Type of the project: Construction of buildings;

- Location of the project: United States of America;

- Project size: Size 2.

The major activities, the predicted duration of each activity, and the sequence of activities of the actual project, which were used as the case study, are enumerated in Table 6, where LS is latest start time; 
Table 6. Activity list for construction of building. ${ }^{\text {a }}$

\begin{tabular}{cccccccc}
\hline Activity & Description & Duration $^{\mathbf{b}}$ & IPs & ES & EF & LS & LF \\
\hline A & Site preparation & 2 & - & 0 & 2 & 0 & 2 \\
B & Excavation & 4 & A & 2 & 6 & 2 & 6 \\
C & Foundation & 3 & B & 6 & 9 & 6 & 9 \\
D & Frame & 5 & C & 9 & 14 & 9 & 14 \\
E & Electrical & 1 & D & 14 & 15 & 23 & 24 \\
F & Insulation & 1 & D & 14 & 15 & 20 & 21 \\
G & Roofing & 2 & D & 14 & 16 & 14 & 16 \\
H & Plumbing & 3 & F & 15 & 18 & 21 & 24 \\
I & Masonry & 6 & E, G,H & 18 & 24 & 24 & 30 \\
J & Carpentry & 4 & G & 16 & 20 & 16 & 20 \\
K & Painting & 7 & J & 20 & 27 & 20 & 27 \\
L & Finishing & 2 & K & 27 & 29 & 27 & 29 \\
M & Cleaning & 1 & L & 29 & 30 & 29 & 30 \\
\hline activity list adopted from Brien and Plotnick [9]. & & & & & \\
b Duration in weeks. & & & & & &
\end{tabular}

IPs is immediate predecessors; ES is earliest start time; $\mathrm{LF}$ is latest finish time; and EF is earliest finish time.

As shown in Figure 2, the numbers in circles are nodes points that represent milestones in the project, from which the existence of a logical loop in the network can be predicted. Three dummy's activities, i.e. activities 6-9, 8-9, and 11-14, have been provided to show interrelationship between the activities. As exposed on network diagram, there are no projected or forecasted delays in any of the activities. But delays are part of construction industry and unfortunately during this project, 2 injuries and illnesses occurred (activities D \& K) delaying the project for one week with additional cost amounting to USD 5,000.00.

To determine the Safety Factor for this project, the necessary data such as factored size of manpower and average rate of injuries and illnesses of activities, which were calculated in the previous section, are incorporated into the actual data of project, as listed in Table 7 .

1. Calculate the Safety Factor of the whole project and critical path:

$$
S F p=N w \times F s w \times T \times \text { Rave, }
$$

where:

- Nw: Number of manpower (30 manpower)

- Fsw: Factored size of workers (size 2)

- T: Project duration (30 weeks)

- Rave: Average rate of the project

However, it is required to compute the average percentage rate of the project (all activities) and average percentage rate of critical activities, as follows.

2. Average percentage rate of project, $\%$ Rave( $p)$ :

$$
\begin{aligned}
\% \text { Rave }(p) & =\frac{\text { Total percentage of all activities }}{\text { Total number of activities }} \\
& =\frac{60.01 \%}{13}=4.62 \% .
\end{aligned}
$$

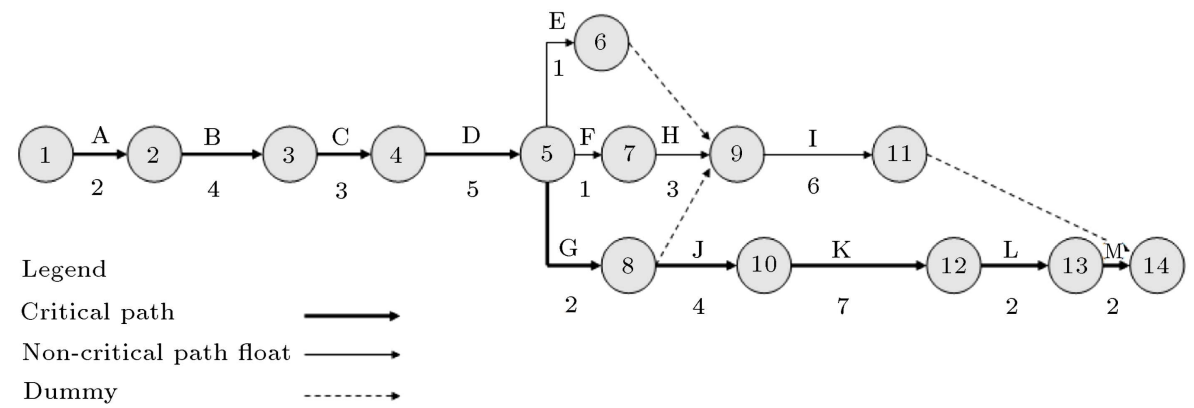

Figure 2. Normal network diagram. 
Table 7. Average rate of injuries and illnesses and number of manpower of each activity.

\begin{tabular}{ccccc}
\hline Activity & Description & Duration & $\begin{array}{c}\text { Ave. percentage } \\
\text { rates (Rave) }\end{array}$ & $\begin{array}{c}\text { Number of } \\
\text { manpower (Nm) }\end{array}$ \\
\hline A $^{*}$ & Site preparation & $\mathbf{2}$ & $\mathbf{3 . 6 \%}$ & $\mathbf{5}$ \\
$\mathbf{B}^{*}$ & Excavation & $\mathbf{4}$ & $\mathbf{5 . 0 2 \%}$ & $\mathbf{1 0}$ \\
$\mathbf{C}^{*}$ & Foundation & $\mathbf{3}$ & $\mathbf{5 . 0 2 \%}$ & $\mathbf{1 0}$ \\
$\mathbf{D}^{*}$ & Frame & $\mathbf{5}$ & $\mathbf{4 . 0 6 \%}$ & $\mathbf{1 5}$ \\
E & Electrical & 1 & $9.22 \%$ & 5 \\
F & Insulation & 1 & $6.87 \%$ & 5 \\
$\mathrm{G}^{*}$ & Roofing & $\mathbf{2}$ & $\mathbf{3 . 6 2 \%}$ & $\mathbf{1 0}$ \\
H & Plumbing & 3 & $14.27 \%$ & 5 \\
I & Masonry & 6 & $3.01 \%$ & 15 \\
$\mathbf{J}^{*}$ & Carpentry & $\mathbf{4}$ & $\mathbf{2 . 1 9 \%}$ & $\mathbf{1 0}$ \\
$\mathbf{K}^{*}$ & Painting & $\mathbf{7}$ & $\mathbf{1 . 6 \%}$ & $\mathbf{1 5}$ \\
$\mathbf{L}^{*}$ & Finishing & $\mathbf{2}$ & $\mathbf{1 . 1 1 \%}$ & $\mathbf{1 0}$ \\
$\mathbf{M}^{*}$ & Cleaning & $\mathbf{1}$ & $\mathbf{0 . 4 2 \%}$ & $\mathbf{5}$ \\
Total & & 30 & $60.01 \%$ & \\
\hline
\end{tabular}

*: Critical activities.

Table 8. The Safety Factor of critical activities.

\begin{tabular}{ccccc}
\hline Activity & $\begin{array}{c}\text { Duration } \\
(\mathbf{N d})\end{array}$ & $\begin{array}{c}\text { Ave. percentage } \\
\text { rates (Rave) }\end{array}$ & $\begin{array}{c}\text { Number of } \\
\text { workers (Nw) }\end{array}$ & $\begin{array}{c}\text { Safety } \\
\text { Factor (SF) }\end{array}$ \\
\hline A & 2 & $3.6 \%$ & 5 & 0.36 \\
B & 4 & $5.02 \%$ & 10 & 2 \\
C & 3 & $5.02 \%$ & 10 & 1.5 \\
D & 5 & $4.06 \%$ & 15 & 3 \\
G & 2 & $3.62 \%$ & 10 & 0.72 \\
J & 4 & $2.19 \%$ & 10 & 0.88 \\
K & 7 & $1.6 \%$ & 15 & 1.68 \\
L & 2 & $1.11 \%$ & 10 & 0.22 \\
M & 1 & $0.42 \%$ & 5 & 0.21 \\
Total & $\mathbf{3 0}$ & $\mathbf{2 6 . 6 4 \%}$ & & $\mathbf{1 0 . 5 7}$ \\
\hline
\end{tabular}

3. Average percentage rate of critical activities; $\%$ Rave(c):

$$
\begin{aligned}
\% \text { Rave }(c) & =\frac{\text { Total percentage of critical activities }}{\text { Total number of critical activities }} \\
& =\frac{26.64 \%}{9}=2.96 \%
\end{aligned}
$$

4. Safety factor of project, SFp:

$$
\begin{aligned}
S F p= & N w \times F s w \times T \times \text { Rave }=30 \times 0.039 \\
& \times 30 \times 0.0462=1.62 \text { weeks } .
\end{aligned}
$$

5. Safety factor of critical path:

$$
\begin{aligned}
S F c= & N w \times F s w \times T \times \text { Ravec }=30 \times 0.039 \\
& \times 30 \times 0.0296=1.04 \text { weeks. }
\end{aligned}
$$

Safety Factors of the critical activities of the project are calculated and listed in Table 8.

Note that in computing the SF of each activity, the employment size (Es) value is not necessary because it is applicable only for the whole project. For example for Activity A (site preparation):

$$
S F=N w \times T \times \text { Rave }=5 \times 2 \times 0.036=0.36 \text { weeks, }
$$

and so on. 
6. Calculate the percent of Safety Factor:

$$
\% S F=\frac{S F \text { of each activity }}{\text { total } \mathrm{SF}} \times 100 \% \text {. }
$$

Percentage of critical Safety Factors is calculated by dividing Safety Factor of each critical activity into the total Safety Factor of critical activities as shown in Table 9. For example for activity A:

$$
\begin{aligned}
\% S F= & \frac{S F \text { of each activity }}{\text { total SF }} \times 100 \%=\frac{0.36}{10.57} \\
& \times 100 \%=3.41 \%,
\end{aligned}
$$

and so on.

7. Calculate the forecasted delay:

$$
D=\% S F \times S F C,
$$

where $\% S F$ is percentage of Safety Factor, and $S F c$ is Total critical of Safety Factor. For example, for activity $\mathrm{A}$ :

$$
D=\% S F \times S F c=0.0341 \times 1.04=0.04 \text { weeks },
$$

and so on.
8. Calculate the safety duration, $\mathrm{Sd}$ :

$$
S d=D-N d,
$$

where $N d$ is normal duration, and $D$ is delay. For example, for activity A:

$$
S d=D-N d=2-0.04=1.96 \text { weeks, }
$$

and so on.

Based on the safety duration of each activity, it is time to modify the activity list:

1. The color coding of one activity differs from that of the other activity. This is because the color coding activities in construction industry (Figure 1) that the researcher assigned depending on their percentage (\%) rate of injuries and illnesses may prevent using the safety process and risk process (Table 5);

2. The new projected duration is able to cover any delays that may occur in the project. This is because of the calculated safety duration as shown in Table 10;

Table 9. The percentage of Safety Factor of critical activities.

\begin{tabular}{cccccc}
\hline Activity & $\begin{array}{c}\text { Duration } \\
(\mathbf{N d})\end{array}$ & $\begin{array}{c}\text { Ave. percentage } \\
\text { rates (Rave) }\end{array}$ & $\begin{array}{c}\text { Number of } \\
\text { workers (Nw) }\end{array}$ & $\begin{array}{c}\text { Safety } \\
\text { Factor (SF) }\end{array}$ & $\begin{array}{c}\text { Percentage of Safety } \\
\text { Factor (\%SF) }\end{array}$ \\
\hline A & 2 & $3.6 \%$ & 5 & 0.36 & $3.41 \%$ \\
B & 4 & $5.02 \%$ & 10 & 2 & $18.92 \%$ \\
C & 3 & $5.02 \%$ & 10 & 1.5 & $14.19 \%$ \\
D & 5 & $4.06 \%$ & 15 & 3 & $28.38 \%$ \\
G & 2 & $3.62 \%$ & 10 & 0.72 & $6.81 \%$ \\
J & 4 & $2.19 \%$ & 10 & 0.88 & $8.33 \%$ \\
K & 7 & $1.6 \%$ & 15 & 1.68 & $15.89 \%$ \\
L & 2 & $1.11 \%$ & 10 & 0.22 & $2.08 \%$ \\
M & 1 & $0.42 \%$ & 5 & 0.21 & $1.99 \%$ \\
Total & $\mathbf{3 0}$ & $\mathbf{2 6 . 6 4 \%}$ & & $\mathbf{1 0 . 5 7}$ & $\mathbf{1 0 0 \%}$ \\
\hline
\end{tabular}

Table 10. Safety duration of critical activities and project.

\begin{tabular}{cccccccc}
\hline Activity & $\begin{array}{c}\text { Duration } \\
\text { (Nd) }\end{array}$ & $\begin{array}{c}\text { Ave. percentage } \\
\text { rates (Rave.) }\end{array}$ & $\begin{array}{c}\text { Number of } \\
\text { workers (Nw) }\end{array}$ & $\begin{array}{c}\text { Safety } \\
\text { Factor (SF) }\end{array}$ & $\begin{array}{c}\text { Percentage of } \\
\text { Safety Factor (\%SF) }\end{array}$ & $\begin{array}{c}\text { Delay } \\
\text { (D) }\end{array}$ & $\begin{array}{c}\text { Safety } \\
\text { duration (Sd) }\end{array}$ \\
\hline A & 2 & $3.6 \%$ & 5 & 0.36 & $3.41 \%$ & 0.04 & 1.96 \\
B & 4 & $5.02 \%$ & 10 & 2 & $18.92 \%$ & 0.2 & 3.8 \\
C & 3 & $5.02 \%$ & 10 & 1.5 & $14.19 \%$ & 0.15 & 2.85 \\
D & 5 & $4.06 \%$ & 15 & 3 & $28.38 \%$ & 0.29 & 4.71 \\
G & 2 & $3.62 \%$ & 10 & 0.72 & $6.81 \%$ & 0.07 & 1.93 \\
J & 4 & $2.19 \%$ & 10 & 0.88 & $8.33 \%$ & 0.09 & 3.91 \\
K & 7 & $1.6 \%$ & 15 & 1.68 & $15.89 \%$ & 0.16 & 6.84 \\
L & 2 & $1.11 \%$ & 10 & 0.22 & $2.08 \%$ & 0.02 & 1.98 \\
M & 1 & $0.42 \%$ & 5 & 0.21 & $1.99 \%$ & 0.02 & 0.98 \\
Total & $\mathbf{3 0}$ & $\mathbf{2 6 . 6 4 \%}$ & & $\mathbf{1 0 . 5 7}$ & $\mathbf{1 0 0 \%}$ & $\mathbf{1 . 0 4}$ & $\mathbf{2 8 . 9 6}$ \\
\hline
\end{tabular}


Table 11. Activity list with Safety Factor.

\begin{tabular}{cccccccc}
\hline Activity & Description & Duration & IPs & ES & EF & LS & LF \\
\hline A & Site preparation & 1.96 & - & 0 & 1.96 & 0 & 1.96 \\
B & Excavation & 3.8 & A & 1.96 & 5.76 & 1.96 & 5.76 \\
C & Foundation & 2.85 & B & 5.76 & 8.61 & 5.76 & 8.61 \\
D & Frame & 4.71 & C & 8.61 & 13.32 & 8.6 & 13.32 \\
E & Electrical & 1 & D & 13.32 & 14.32 & 21.96 & 22.96 \\
F & Insulation & 1 & D & 13.32 & 14.32 & 18.96 & 19.96 \\
G & Roofing & 1.93 & D & 13.32 & 15.25 & 13.32 & 15.25 \\
H & Plumbing & 3 & F & 14.32 & 17.32 & 19.96 & 22.96 \\
I & Masonry & 6 & E,G,H & 17.32 & 23.25 & 22.96 & 28.96 \\
J & Carpentry & 3.91 & G & 15.25 & 19.16 & 15.25 & 19.16 \\
K & Painting & 6.84 & J & 19.16 & 26 & 19.16 & 26 \\
L & Finishing & 1.98 & K & 26 & 27.98 & 26 & 37.98 \\
M & Cleaning & 0.98 & L & 27.98 & 28.96 & 27.98 & 28.96 \\
\hline
\end{tabular}

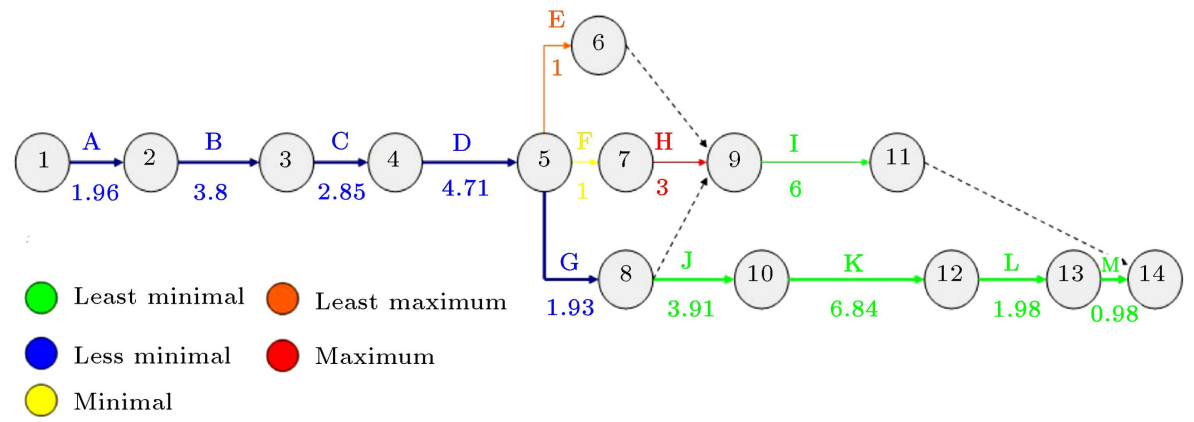

Figure 3. Safety network diagram.

3. The IPs, ES, EF, LS, and LF will have new values because of the calculated safety duration using the Safety Factor.

The activity list with Safety Factor in Table 11 shows that by using the Safety Factor in the CPM technique, the project could still be completed on time, even when two incidents of injuries and illnesses occurred and delayed the project for one week. Therefore, due to change or new duration, it is required to revise the conventional CPM in Safety Network Diagram to identify the accident category of each activity and determine the appropriate precautionary action, mitigating risk of project as shown in Figure 3 .

\section{Verification of research}

The researcher evaluated and verified the progress of the improved CPM by using a control tool commonly known as the Status Index (SI) in terms of the efficiency of project [12]. The Status Index (SI) is a means of relating actual progress and costs versus the project plan calculated by Eq. (12):

$$
\text { Status index }=\frac{\text { Progress }}{\text { Scheduled }} \times \frac{\text { Budget }}{\text { Actual expenditures }} \text {. }
$$

Based on project specification of the case study represented in Table 12, the status index of project by

Table 12. Summary of the case study.

\begin{tabular}{lcccc}
\hline \multicolumn{1}{c}{ Project } & Cost $(\$)$ & Time (day) & Variation cost & Variation time \\
\hline Estimated project (normal) & $\$ 150,000$ & 180 & $0 \%$ & $0 \%$ \\
Actual project with 2 accidents occurred & $\$ 155,000$ & 186 & $-6.67 \%$ & $-6.67 \%$ \\
Simulated actual project with 2 & & & & $-0 \%$ \\
accidents occurred and integrated & $\$ 150,000$ & 180 & & \\
Safety Factor in project & & & & \\
\hline
\end{tabular}


using the conventional CPM is 0.94 or $93.65 \%$ because of the 2 occurred injuries and illnesses, delaying the project for one week and amounting the additional cost to USD 5,000.00. Conversely, by applying Safety Factor to CPM, when two (2) accidents occurred on site, the SI of the project increased to 1.0 or $100 \%$ and the cost of the project remained as budgeted.

\section{Conclusion}

The presented new critical path method in which the total safety and duration of the project is fairly distributed in all critical activities is shorter in duration than the normal critical path method. The critical path method with safety duration or Safety Factor also proved that the construction delay could be fairly distributed in other activities with minimum cost of delay per day. Instead of concentrating only on the particular activities with great impact or effect on other or succeeding activities, the researcher adopted the concept of Yi and Langford [3]: "One of the measures for evading such hazardous situations is to predict such situations and to reschedule the start time of high-risk situation so that risks are not concentrated during certain periods and at certain locations. In order to predict when and where the risk will reach its highest level, analysis should be performed based upon various information, including statistical sources such as accident histories, and this should be done in coordination with the activity scheduling."

The method is supported by the space scheduling problem that Winch and North [4] emphasized due to the sophisticated methods of planning and analyzing the sequence of tasks within the work breakdown structure through time; but the problem of planning where on site those tasks are to be executed is not well-supported, especially because those spaces are as dynamic as the project progresses, which in this study are called critical activities. Through distribution of delay by using the computed safety duration, the researcher was able to mark up or maximize the available space in each activity, allocate tasks to spaces, and analyze and optimize space loading in relation to the critical path.

In light of the above findings presented on how to manage construction delays using the new improved scheduling technique of Critical Path Method (CPM) by Safety Factor, the following conclusions were derived:

- The application of the 5 colors coding in the CPM diagram enabled the readers to visibly identify the degree of potential hazard of each activity and increase awareness/alertness, particularly to the most risky activities;

- The application of safety process and risk process provided the Project Owners/Contractors/Engineers with the benefit of color coding categories in the construction industry to determine the appropriate safety process and risk process for protecting their interest and avoiding costly disputes;

- The identification of categories and calculation of Safety Factors, particularly in critical activities, have great advantages to forecast and plan the appropriate solutions or actions even before the project implementation;

- It is vital to use the latest statistics to calculate the safety duration and determine the Safety Factor of all construction activities before incorporating the Safety Factor into the CPM diagram to adequately determine the appropriate solutions or actions and, most importantly, appreciate the benefits of this study;

- The application of Safety Factor in CPM scheduling technique, even before the construction of a particular activity, increases the safety and, most importantly, decreases the risk in the construction project;

- Finally, the applied dynamic to manage construction delays using the Safety Factor in Critical Path Method (CPM) increased the efficiency of the project progress, awareness in advanced monitoring/controlling of each construction activity without any additional cost incurred to construction project, and quality level of management.

\section{References}

1. O'Brien, J.J. and Plotnick, F.L., CPM in Construction Management, 6th Ed., McGraw-Hill Company, Inc., New York, USA (2006).

2. Schexnayder, C.J., Fiori, C. and Mayo, R., Construction Management Fundamentals, 2nd Ed., pp. 72-84, McGraw-Hill Education, New York, USA (2008).

3. Bubshait, A.A. "Comparison of delay analysis methodologies", Journal of Construction Engineering and Management, 124(4), pp. 315-322 (1998).

4. Yi, K.J. and Langford, D. "Scheduling-based risk estimation and safety planning for construction projects", Journal of Construction Engineering and Management, 132(6), pp. 626-635 (June 2006).

5. Winch, G.M. and North, S. "Critical space analysis", Journal of Construction Engineering and Management, 132(5), pp. 473-481 (May 2006).

6. Saurin, T.A., Formoso, C.T., Soares, A.C. and Guimarães, L.M. "Integrating safety into 3 production 
planning and control: An empirical study in the refurbishment of an industrial building", Construction Safety Management System, 1st Ed., pp. 195-210, Taylor and Francis, London (2004).

7. Calderon, J.F. and Gonzales, E.C., Methods of Research and Thesis Writing, pp. 28-32, National Book Store (2008).

8. United States Department of Labor, Bureau of Labor Statistics, Nonfatal Occupational Injuries and Illnesses Data 2001-2013 [Cited 2015, June 7], Available from URL: http://www.bls.gov/iif/.

9. Project Management Institute, A Guide to the Project Management Body of Knowledge (PMBOK Guide), 5th Ed., Chapter 11, Newtown Square, Pa: Project Management Institute, USA (2004).

10. Levy, S.M., Project Management in Construction, 5th Ed., Chapter 13, McGraw-Hill Companies, Inc. (2006).

11. Smith, N.J., Merna, T. and Jobling, P., Managing Risk: In Construction Projects, 2nd Ed., Chapter 3, Wiley-Blackwell (2009).

12. Ritz, G. and Levy, S., Total Construction Project Management, 2nd Ed., pp. 91-94, McGraw-Hills Professional (1994).

\section{Biography}

Alireza Moghayedi received his BSc in Civil Engineering from Azad University of Iran in 2004, MSc in Construction Management from the University of the East, Philippines, and MSc in Civil Engineering, Major in Transportation, from University of the Philippines in 2010 and 2013, respectively. Also, he is a candidate for PhD in Civil Engineering, Major in Transportation, at University of the Philippines. From year 2010 to 2013 , he was a faculty member, director of mathematics program at several times, a founder of mathematics consulting group, and an author of Pre-College Mathematics to evaluate and improve the knowledge of mathematics and talent of Filipino college students at Far Eastern University, Philippines. He was a coadviser in Graduate School at University of the East, Philippines, from 2010 to 2012. And lastly, he was a co-adviser in the College of Engineering at University of the Philippines from 2012 to 2014.

Alireza Moghayedi is currently a director of research and technical studies in the Department of Road and Urban Development of Iran (Khorasan Razavi). 